\title{
Enhanced Cell Proliferation on Biomedical Titanium Surfaces by Laser Ablation- Induced Micro- and Nanoscale Hybrid Structures
}

\author{
Hwa-Teng Lee*1 and Ching-Chi Lin*2 \\ Department of Mechanical Engineering, National Cheng Kung University, No. 1, University Road, Tainan 701, Taiwan, R. O. China
}

\begin{abstract}
The cell proliferation performance of pure titanium substrates was enhanced by modifying the surface morphology using an ultraviolet laser with a wavelength of $355 \mathrm{~nm}$ and travel speeds ranging from $10 \sim 300 \mathrm{~mm} / \mathrm{sec}$. Rat calvarial osteoblast cells were cultured on the sample surfaces for 1 7 days. The cell proliferation was investigated via 3-(4,5-Dimethylthiazol-2-yl)-2,5-diphenyl tetrazolium bromide (MTT) assays. Scanning electron microscopy observations showed that the laser ablation (LA) surfaces had a hybrid micro- and nanoscale structure consisting of microscale grooves with nanoscale agglomerations on their surface. For a low laser travel speed of $10 \mathrm{~mm} / \mathrm{sec}$, the grooves had a width of approximately $5.44 \sim 10.03 \mu \mathrm{m}$. For the maximum travel speed of $300 \mathrm{~mm} / \mathrm{sec}$, the grooves reduced in height, but increased in width to around $10.97 \sim 20.06 \mu \mathrm{m}$. The agglomerations on the grooves had a size of around 30 100 nm; with larger agglomerations being formed at a lower laser travel speed. The XRD analysis results revealed the presence of titanium compounds ( $\mathrm{TiO}$ and $\left.\mathrm{TiN}_{0.3}\right)$ on the LA surfaces ablated at lower travel speeds of $10 \mathrm{~mm} / \mathrm{sec}$ and $50 \mathrm{~mm} / \mathrm{sec}$, respectively. The MTT measurements showed that the LA samples yielded a better cell proliferation rate than a sandblasted acid-etched titanium sample or a machined titanium sample. Furthermore, the cell proliferation rate increased with a decreasing laser travel speed. In general, the present results confirm the feasibility of laser ablation surface modification as a means of promoting the cell proliferation rate on titanium bioimplants. [doi:10.2320/matertrans.ME201909]
\end{abstract}

(Received January 9, 2019; Accepted February 22, 2019; Published July 5, 2019)

Keywords: titanium bioimplants, UV laser, laser ablation, rat calvarial osteoblast cells, cell proliferation

\section{Introduction}

Titanium and its alloys are widely used as endosseous implants in dentistry due to their favorable biocompatibility, corrosion resistance and mechanical properties. ${ }^{1,2)}$ However, titanium is bioinert, and hence some form of surface modification is required to enhance the osseointegration performance. Previous studies ${ }^{2-4)}$ have shown that modifying the surface topography, or depositing bioactive material coatings, can significantly improve the adhesion, proliferation and differentiation of cells seeded on titanium surfaces. However, further improvements in the osseointegration performance are still required to shorten the healing time and improve the bonding strength of the implant to the bone tissue. $^{5)}$

Most commercially available dental implants feature some form of surface modification to enhance their surface roughness. Several studies have shown that micro- and nanoscale surface roughness is beneficial in enhancing the osseointegration and biomechanical fixation of dental implant materials both in vitro and in vivo. ${ }^{6,7)}$ Moreover, changing the surface composition by using physiochemical methods to induce titanium oxide layers, or bond functional groups to the surface, also appears to provide a promising approach for stimulating cell activity. ${ }^{8,9}$ Laser ablation (LA) is a convenient and straightforward means of patterning biomedical substrates with microscale surface roughness. ${ }^{10)}$ Mwenifumbo et al. showed that the micro-groove texture obtained by LA processing results in a strong orientation of the cells in the groove direction. ${ }^{11)}$ The literature contains many studies on the use of ultraviolet (UV) lasers to pattern micro grooves with various geometries and textures on titanium surfaces. ${ }^{11-16)}$

\footnotetext{
${ }^{* 1}$ Corresponding author, E-mail: htlee@mail.ncku.edu.tw

${ }^{* 2}$ Graduate Student, National Cheng Kung University
}

Previous studies on the cell proliferation effect of micrometer and nanometer structures have considered the use of both chemical methods ${ }^{17)}$ and laser ablation methods ${ }^{10)}$ to modify the surface. The chemical methods produced irregular micro-pits or dimple-like micrometer- and nanometer-hybrid structures. By contrast, the laser ablation methods produced regular microscale or nanoscale geometries. Thus, while the effects of micrometer- and nanometer-hybrid structures produced by chemical methods on the cell behavior (proliferation) are reasonably clear, the literature lacks a detailed investigation into the interaction effect between laser ablation-induced micrometer- and nanometer-hybrid structures and cells. Moreover, many studies have examined the growth behavior of biological cells on material surface using fibroblasts, human bone osteosarcoma cell line MG-63, and osteoblastic cell line MC3T3-E1. ${ }^{10,15,18)}$ However, the effects of the morphology and size of the micrometer- and nanometer-hybrid structures produced by laser ablation on the adhesion and proliferation of osteoblast cells are not yet fully understood.

Accordingly, in the present study, titanium substrates were treated by UV laser ablation with travel speeds in the range of $10 \sim 300 \mathrm{~mm} / \mathrm{sec}$ to investigate the effect of the resulting micro- and nanoscale hybrid surface structures on the cell proliferation behavior. The effects of surface structure scale and process parameters on cell growth were investigated. The microstructure, chemical composition and Ti compounds formed on the LA surfaces were investigated by optical microscopy (OM), scanning electron microscopy (SEM), energy-dispersive X-ray spectroscopy (EDS) and X-ray diffraction (XRD). Rat calvarial osteoblast cells were cultured on the various samples for $1 \sim 7$ days. The proliferation of the cells on the sample surfaces was examined by means of MTT (3-(4,5-Dimethylthiazol-2-yl)-2,5-diphenyl tetrazolium bromide) dye-reduction assays. The results showed that the cells exhibited a significantly better adhesion and prolifer- 


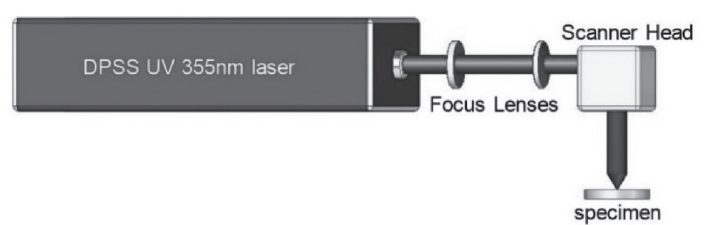

(a)

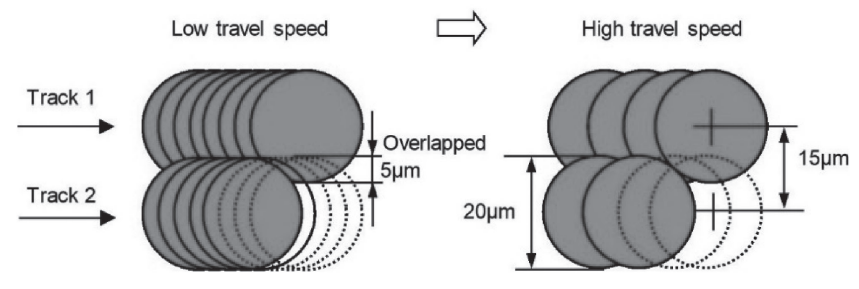

(b)

Fig. 1 Schematic illustrations showing: (a) laser ablation system; and (b) low and high speed laser travel paths.

ation behavior than those seeded on sandblasted acid-etched (SA) or machined (MA) titanium surfaces, respectively.

\section{Material and Methods}

\subsection{Sample preparation}

Disks with a thickness of $1 \mathrm{~mm}$ were cut from commercially pure titanium rods (ASTM Grade 4) with a 5-mm diameter (Carpenter Technology Corporation, America). The disks were irradiated by a UV laser with a wavelength of $355 \mathrm{~nm}$ and a pulse duration of $25 \mathrm{~ns}$ (Fig. 1(a)). The ablation process was performed using three different travel speeds (i.e., 10, 50 and $300 \mathrm{~mm} / \mathrm{sec}$ ) and a constant focus length of $185 \mathrm{~mm}$. For all of the ablation trials, the laser spot size was set as $20 \mu \mathrm{m}$ while the scan space was set as $15 \mu \mathrm{m}$ (Fig. 1(b)). The processing parameters are summarized in Table 1. The surface morphologies and biocompatibility of the LA samples were compared with those of the SA and MA samples, respectively. The SA sample was sandblasted using $\mathrm{Al}_{2} \mathrm{O}_{3}$ grit $(200 \sim 300 \mu \mathrm{m})$ and then etched with hydrochloric and sulfuric acid solution. The MA sample was machined to a smooth surface finish by a lathe finishing process.

\subsection{Surface characterization and component analysis}

The surface morphologies and chemical compositions of the various samples were examined by field emission SEM (FE-SEM, Hitachi-4700, Japan) and EDS, respectively. The depth-to-width ratios of the grooves formed on the surfaces of the LA samples were measured by a stereo zoom OM (Leitz Metallux3, America). Finally, the phases on the sample surfaces were identified by XRD $(\mathrm{Cu} \mathrm{K} \alpha$ radiation, Rigaku D/Max III.V, Rigaku Ltd., Japan) with a $2 \theta$ scanning range of $20 \sim 80^{\circ}$ and a scanning rate of $2^{\circ} \mathrm{min}^{-1}$.

\subsection{Cell assays}

The cell proliferation performance of the various samples was evaluated by quantifying the proliferation of neonatal rat calvarial osteoblasts on the sample surface by means of MTT dye-reduction assays. Briefly, the skulls were cut into fragments and washed several times with phosphate buffer
Table 1 Laser ablation parameters.

\begin{tabular}{lc}
\hline Processing parameters & Value \\
\hline Average power $(\mathrm{W})$ & 1 \\
Wavelength $(\mathrm{nm})$ & 355 \\
Track spacing $(\mu \mathrm{m})$ & 15 \\
Spot size $(\mu \mathrm{m})$ & 20 \\
Focus length $(\mathrm{mm})$ & 185 \\
Travel speed $(\mathrm{mm} / \mathrm{sec})$ & $10 / 50 / 300$ \\
\hline
\end{tabular}

solution. The dissolved skull fragments were added to type I collagenase and the mixture was stored in an incubator at $37^{\circ} \mathrm{C}$ for 15 minutes. The skull tissue was then removed and added to new collagenase. The sample was stored in an incubator at $37^{\circ} \mathrm{C}$ for 2 hours and was then cultured with Dulbecco's Modified Eagle Medium (DMEM) supplement containing $10 \%$ fetal bovine serum in a humidified incubator with $5 \% \mathrm{CO}_{2}$ at $37^{\circ} \mathrm{C}$. The osteoblast cells were seeded on titanium discs (LA, SA and MA) placed in a 48-well polystyrene plate with a density of $10^{4}$ cells/well. The disks were incubated in culture medium (DMEM) for 1, 3, 5 and 7 days, respectively. After the designated culture period, the medium was removed and the disks were flushed several times with phosphate buffer solution. The solution was then replaced with MTT solution for testing purposes. After three hours, the medium was removed from the well and dimethyl sulfoxide (DMSO) was added to dissolve the precipitate. The optical density (OD) of the various samples was examined using an enzyme-linked immuno-sorbent assay (ELISA) reader with a test wavelength of $570 \mathrm{~nm}$. Statistical analyses were performed using Minitab $^{\circledR}$ software Version 18.1 (Minitab Inc., State College, Pennsylvania, USA). The optical density values of the different samples were analyzed using standard analysis of variance (ANOVA) techniques with a statistical significance level of $\mathrm{P}<0.05$ and a high statistical significance level of $\mathrm{P}<0.001$.

\section{Results and Discussion}

\subsection{Surface morphology}

Figure 2 presents SEM micrographs showing the surface morphologies of the LA, SA and MA samples. The LA sample ablated with a travel speed of $10 \mathrm{~mm} / \mathrm{sec}$ contains deep and narrow grooves with a width of approximately 5.44 10.03 $\mu \mathrm{m}$ (Fig. 2(a)). As the travel speed is increased to $50 \mathrm{~mm} / \mathrm{sec}$, the groove width increases to around $9.84 \sim$ $16.88 \mu \mathrm{m}$ (Fig. 2(b)). Finally, for the maximum travel speed of $300 \mathrm{~mm} / \mathrm{sec}$, the grooves are shallower and the width increases to approximately $10.97 \sim 20.06 \mu \mathrm{m}$ (Fig. 2(c)). In contrast to the LA samples, the surface of the SA sample contains irregular micro-pits or dimple-like structures with a size of around $0.29 \sim 2.58 \mu \mathrm{m}$ (Fig. 2(d)). Finally, the MA sample has a smooth surface with only minor scratches (Fig. 2(e)). (Note that a detailed analysis of the surface metrology of the various samples is shown in Table 2.)

In the LA process, the heat input to the sample surface is determined mainly by the laser travel speed. In particular, at 


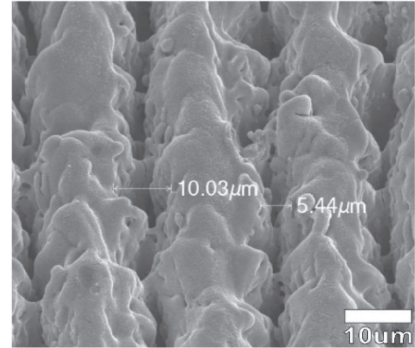

(a)

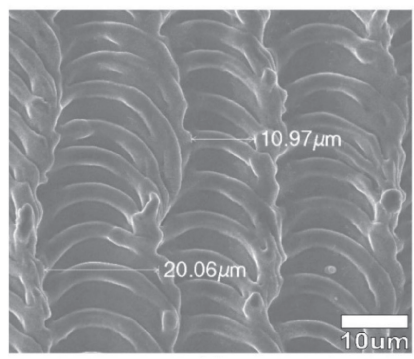

(c)

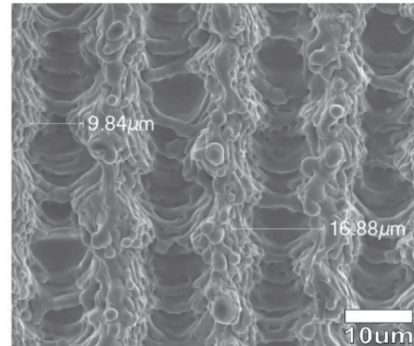

(b)

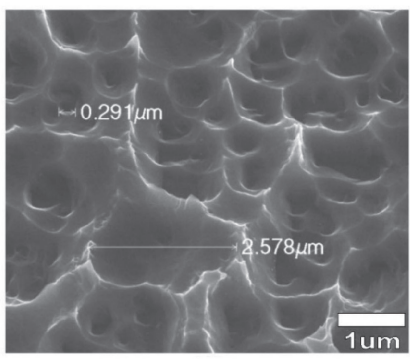

(d)

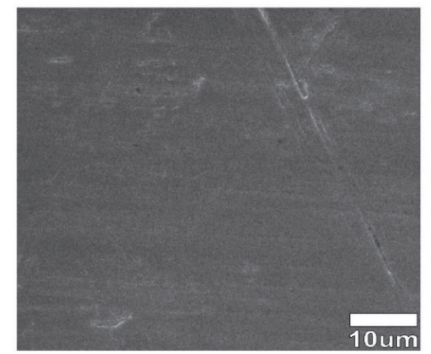

(e)

Fig. 2 SEM images of microscale structure surfaces. LA surfaces processed with laser travel speeds of (a) $10 \mathrm{~mm} / \mathrm{sec}$, (b) $50 \mathrm{~mm} / \mathrm{sec}$, and (c) $300 \mathrm{~mm} / \mathrm{sec}$. (d) SA surface. (e) MA surface. LA surfaces in (a) and (b) have deep and parallel groove geometry, while that in (c) has shallow wave geometry. By contrast, SA surface contains irregular micropits, while MA surface has smooth and regular appearance.

low speeds (i.e., $10 \mathrm{~mm} / \mathrm{sec}$ and $50 \mathrm{~mm} / \mathrm{sec}$ ), the heat energy density per pulse is increased, and hence the material surface undergoes a greater melting effect. Moreover, the melt pools
Table 2 Surface metrology results for MA, SA and LA samples.

\begin{tabular}{ccccc}
\hline Samples & & Width $(\boldsymbol{\mu m})$ & Depth $(\boldsymbol{\mu m})$ & D/W ratio \\
\hline MA & & - & - & 0.00 \\
\hline SA & 10 & $7.74 \pm 2.31 \pm 1.1$ & $0.7 \pm .01$ & 0.50 \\
\hline \multirow{2}{*}{ LA } & 50 & $13.36 \pm 3.52$ & $8.9 \pm 0.3$ & 0.67 \\
Travel speed $(\mathrm{mm} / \mathrm{sec})$ & 300 & $15.52 \pm 4.55$ & $4.5 \pm 0.3$ & 0.29 \\
\hline
\end{tabular}

formed in successive pulses overlap, and hence a groove-like geometry is produced as the laser beam travels over the sample surface. However, at high travel speeds (i.e., $300 \mathrm{~mm} / \mathrm{s}$ ), the heat energy density per pulse reduces, and consequently, the melt pool depth also reduces. Furthermore, the melt pools are more widely separated, and hence a series of shallow ripples are produced on the sample surface.

Figure 3 presents OM images of the LA, SA and MA sample cross-sections. A quantitative analysis of the various cross-sections shows that the surfaces of the S10, S50 and S300 samples have a micro scale characteristic (greater than $1 \mu \mathrm{m}$ ) and the depth range was reduced from 35.3 to $4.5 \mu \mathrm{m}$. By contrast, the SA sample has a submicron depth (less than $1 \mu \mathrm{m}$ but greater than $100 \mathrm{~nm}$ ) with an average value of $0.7 \mu \mathrm{m}$ (see Table 2). For the LA samples, the laser ablated depth and depth-to-width $(\mathrm{D} / \mathrm{W})$ ratio increase with a decreasing laser travel speed. However, the $\mathrm{D} / \mathrm{W}$ ratio has a value of just 0.29 at the highest laser speed of $300 \mathrm{~mm} / \mathrm{sec}$. Consequently, the surface has a shallow wave-like morphology (Fig. 3(c)) rather than a deep groove-like structure, as for the samples processed at lower travel speeds of $10 \mathrm{~mm} / \mathrm{sec}$ and $50 \mathrm{~mm} / \mathrm{sec}$, respectively (Figs. 3(a) and 3(b)). The D/W ratio of the SA sample is slightly higher than that of the LA sample processed at $300 \mathrm{~mm} / \mathrm{sec}$, respectively, but is significantly lower than that of the LA sample ablated at $10 \mathrm{~mm} / \mathrm{sec}$. Finally, the MA sample has a smooth surface with a $\mathrm{D} / \mathrm{W}$ ratio equal to zero.

Figures $4(\mathrm{a}) \sim(\mathrm{c})$ present high-magnification SEM images of the groove/wave surfaces of the LA samples ablated at

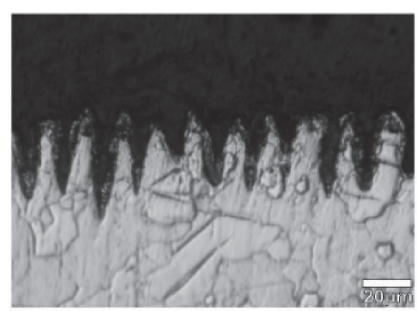

(a)

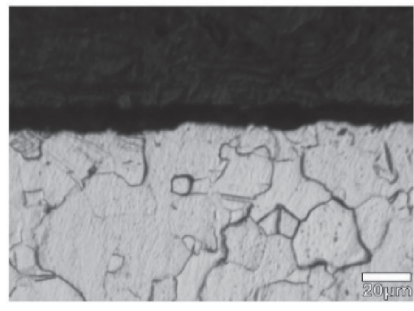

(d)

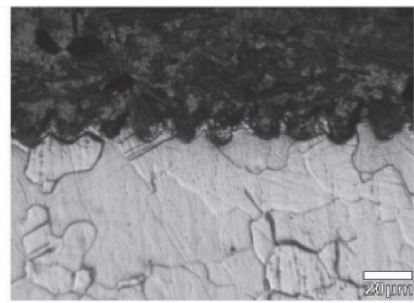

(b)

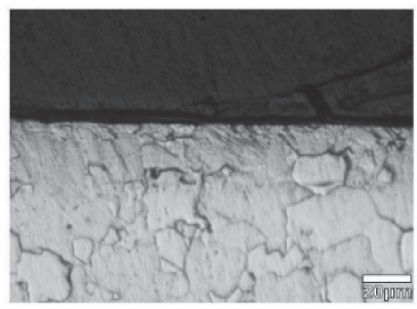

(e)

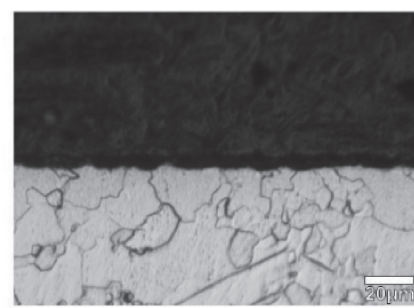

(c)

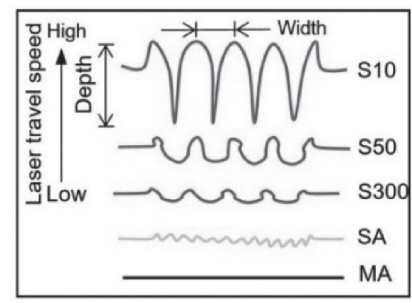

(f)

Fig. 3 Cross-sectional images of LA samples processed with laser travel speeds of: (a) $10 \mathrm{~mm} / \mathrm{s}$, (b) $50 \mathrm{~mm} / \mathrm{s}$, and (c) $300 \mathrm{~mm} / \mathrm{s}$. Crosssectional images of: (d) SA sample and (e) MA sample. (f) Schematic representations of sample cross-sectional profiles. 


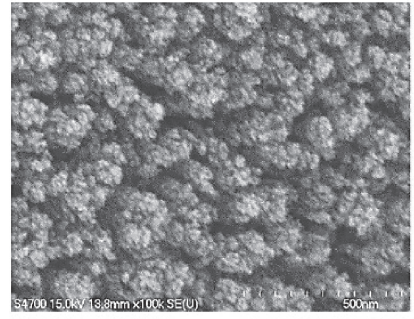

(a)

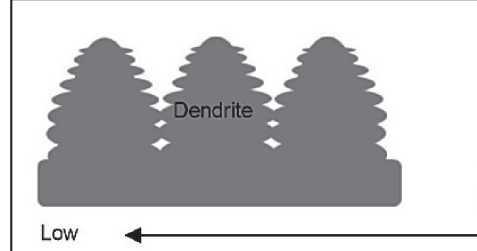

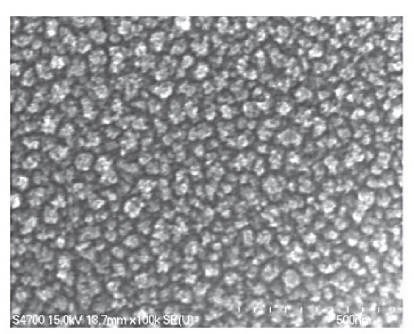

(b)

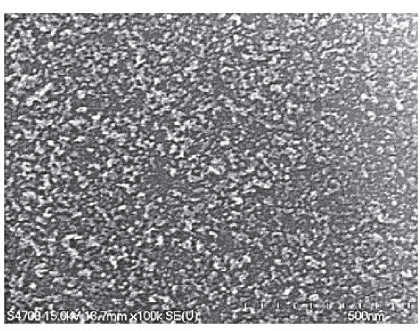

(c)

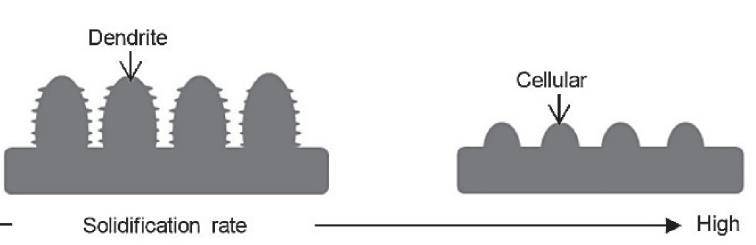

(d)

Fig. 4 SEM observations of nanoscale textures on LA samples processed with travel speeds of: (a) $10 \mathrm{~mm} / \mathrm{sec}$, (b) $50 \mathrm{~mm} / \mathrm{sec}$, and (c) $300 \mathrm{~mm} / \mathrm{sec}$. (d) Schematic representations of corresponding nanostructures.

laser travel speeds of 10,50 and $300 \mathrm{~mm} / \mathrm{sec}$, respectively. The images show that the rapid melting and subsequent solidification of the sample surface results in the formation of agglomerate structures with a nanoscale dimension on the groove surface. ${ }^{19)}$ As the laser travel speed increases, the agglomerate size decreases (see Fig. 4(d)). In particular, the agglomerate size reduces from around $100 \mathrm{~nm}$ at a travel speed of $10 \mathrm{~mm} / \mathrm{sec}$ to just $30 \mathrm{~nm}$ at a speed of $300 \mathrm{~mm} / \mathrm{sec}$.

In general, the results presented in Figs. 3 and 4 confirm the effectiveness of the LA technique in controlling the geometry of the ablated surface (e.g., grooves or waves) and producing a mixed hybrid micro- and nanoscale structure. Previous studies have reported that the geometry and structure of LA surfaces depends on many factors, including the type of laser source, the wavelength, the pulse repetition rate, the travel speed, the pulse duration, and the output power. ${ }^{20)}$ These parameters have a significant effect on both the amount of heat input to the sample and the subsequent cooling rate, and therefore lead to obvious changes in the microstructure, topography and chemical composition of the ablated surface. The adhesion, growth and proliferation of cells on metal and alloy surfaces depend significantly on the surface roughness and geometry. ${ }^{21)}$ Fancsaly et al. ${ }^{20,22)}$ ablated substrates with an IR pulsed laser with a wavelength of $1064 \mathrm{~nm}$ and found that many microscale asperities were produced on and between the ablated grooves on the sample surface. The asperities were found to have an average size of approximately $10-50 \mu \mathrm{m}$. By contrast, in the present study, the agglomerations on the UV laser-ablated surfaces have a characteristic scale in the order of just nanometers. Previous studies have reported that a nanoscale surface texture is beneficial in promoting cell spreading with extended filopodia in the early growth stage. ${ }^{17,23)}$ Hence, it is reasonable to infer that the nanostructures formed on the micro-grooves produced in the present LA samples should also enhance the attachment and differentiation of biological cells. Furthermore, given that the size of the nanostructures increases with a decreasing laser travel speed, it is also reasonable to assume that the LA samples processed at lower speeds of $10 \mathrm{~mm} / \mathrm{sec}$ and $50 \mathrm{~mm} / \mathrm{sec}$, respectively, will provide a better cell proliferation performance (see Section 3.3).

\subsection{EDS and XRD analysis of LA, SA and MA samples}

Figure 5 presents the EDS spectra of the MA, LA and SA samples. The detailed analysis results are presented in Table 3. It is seen that the surfaces of the MA and SA samples are composed exclusively of Ti. By contrast, the LA samples contain both Ti and oxygen (O). Figure 6 shows the XRD patterns of the LA, SA and MA samples. The LA sample processed at the lowest travel speed of $10 \mathrm{~mm} / \mathrm{sec}$ consists of pure $\mathrm{Ti}$ together with $\mathrm{TiO}$ and $\mathrm{TiN}_{0.3}$ phases (see pattern S10). For a higher travel speed of $50 \mathrm{~mm} / \mathrm{sec}$, the surface contains pure $\mathrm{Ti}$ and $\mathrm{TiN}_{0.3}$ phase (see pattern $\mathrm{S} 50$ ). However, for the highest travel speed of $300 \mathrm{~mm} / \mathrm{sec}$, the surface contains only Ti (see pattern S300). In other words, the formation of $\mathrm{TiO}$ and $\mathrm{TiN}_{0.3}$ phases reduces with an increasing travel speed. The $\mathrm{TiO}$ and $\mathrm{TiN}_{0.3}$ phases are produced as a result of the reaction between the Ti content of the ablated surface and the $\mathrm{O}$ and $\mathrm{N}$ contents of the ambient environment. At a higher travel speed, the ablated surface cools more rapidly. Consequently, the reaction time with the environment is reduced, and hence the quantity of formed $\mathrm{TiO}$ and $\mathrm{TiN}_{0.3}$ phase also reduces. $\mathrm{TiO}$ is a metastable phase and thus cannot be reliably detected by EDS (see Fig. 5). However, its existence can be detected and confirmed by XRD (see Fig. 6), as reported also in the literature. ${ }^{24)}$ The MA and SA surfaces consist mainly of Ti (see patterns MA and SA in Fig. 6). However, the SA pattern also contains several small peaks corresponding to $\mathrm{TiH}_{2}$ originating from the hydrochloric and sulfuric solution used in the etching process.

It has been reported that the presence of a titanium oxide layer on the surface of biomedical implants promotes biocompatibility and bone healing. ${ }^{25,26)}$ In addition, titanium oxide has good blood compatibility and corrosion resistance. ${ }^{27)}$ Allegrini et al. $^{28)}$ ablated a titanium surface using a Nd:YAG laser under ambient conditions. The ablated surface was found to have a high oxygen concentration. ${ }^{29}$ By contrast, the LA samples processed in the present study with 


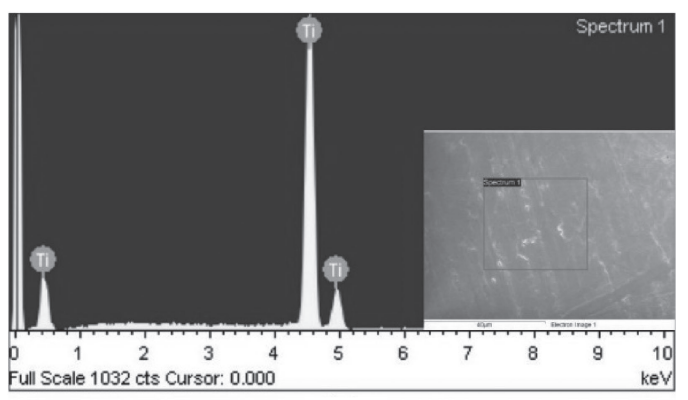

(a)

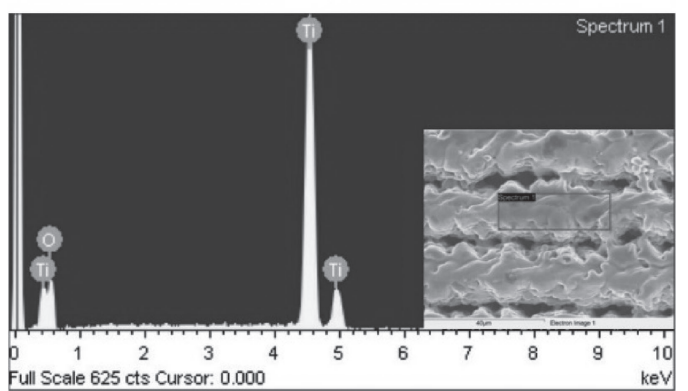

(b)

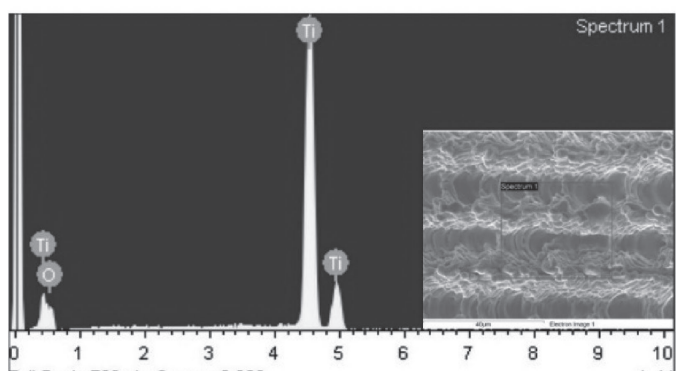

Full Scale 732 cts Cursor: 0.000

(c)

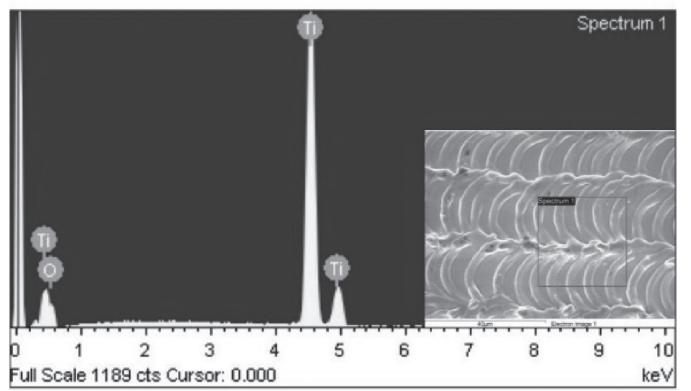

(d)

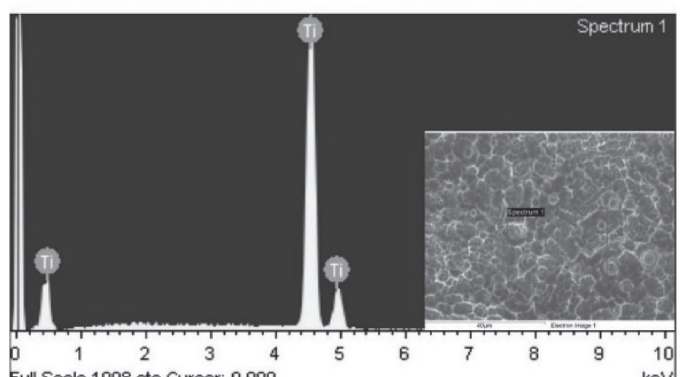

Full Scale 1008 cts Cursor: 0.000

(e)

Fig. 5 EDS spectra of: (a) MA sample; LA samples processed with travel speeds of: (b) $10 \mathrm{~mm} / \mathrm{sec}$, (c) $50 \mathrm{~mm} / \mathrm{sec}$, and (d) $300 \mathrm{~mm} / \mathrm{sec}$; and (e) SA sample.
Table 3 Semi-quantitative EDS analysis results for MA, SA and LA samples.

\begin{tabular}{cccc}
\hline \multirow{2}{*}{ Samples } & & \multicolumn{2}{c}{ Elements content } \\
\cline { 3 - 4 } & & $\mathrm{Ti}$ & $\mathrm{O}$ \\
\hline MA & - & 100.00 & - \\
\hline SA & - & 100.00 & - \\
\hline & 10 & 68.79 & 31.21 \\
\cline { 3 - 4 } LA & 50 & 81.69 & 18.31 \\
\cline { 3 - 4 } Travel speed $(\mathrm{mm} / \mathrm{sec})$ & 300 & 83.86 & 16.14 \\
\hline
\end{tabular}

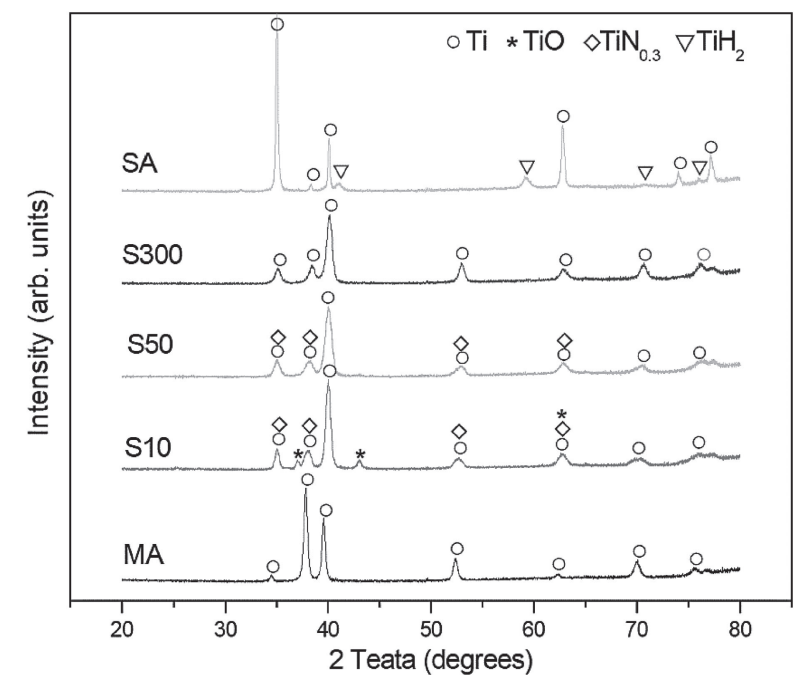

Fig. 6 XRD spectra of: (a) MA sample; LA samples processed with travel speeds of: (b) $10 \mathrm{~mm} / \mathrm{sec}$, (c) $50 \mathrm{~mm} / \mathrm{sec}$, and (d) $300 \mathrm{~mm} / \mathrm{sec}$; and (e) SA sample.

a low laser travel speed (i.e., $10 \mathrm{~mm} / \mathrm{sec}$ and $50 \mathrm{~mm} / \mathrm{sec}$ ) have an oxide layer on the surface, and are hence expected to provide a better cell growth.

\subsection{Cell proliferation}

Figure 7(a) shows the MTT assay results for the LA, SA and MA samples after culturing periods of $1 \sim 7$ days. For all five samples, the cell proliferation increases with an increasing culturing time. For culturing periods of 1 and 3 days, the OD value is less than 0.4 in every case and no significant difference is observed between the cell proliferation rates of the different samples $(p>0.05)$. After 5 days, a significant difference is observed between the MA, LA-S10 and SA samples $(p<0.05)$. However, no statistically significant difference $(p>0.05)$ is noted between the MA, LA-S50 and LA-S300 samples. After 7 days, noticeable differences in the proliferation rates of all the samples are observed. In particular, the OD values of the five samples are ranked as $\mathrm{S} 10>\mathrm{S} 50>\mathrm{S} 300>\mathrm{SA}>\mathrm{MA}$. In other words, the proliferation rates of the samples treated by LA are higher than those of the samples treated by SA or MA. Furthermore, the cell proliferation rate increases as the laser travel speed decreases. The detailed analysis results presented in Fig. 7(b) show that the cell proliferation rate of the LA surface processed at $10 \mathrm{~mm} / \mathrm{sec}$ is significantly higher than that of 


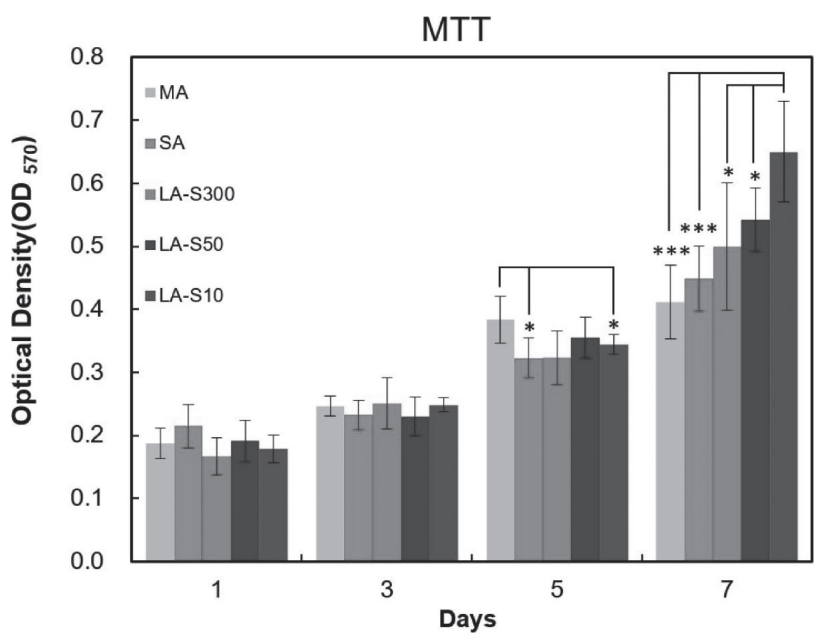

(a)

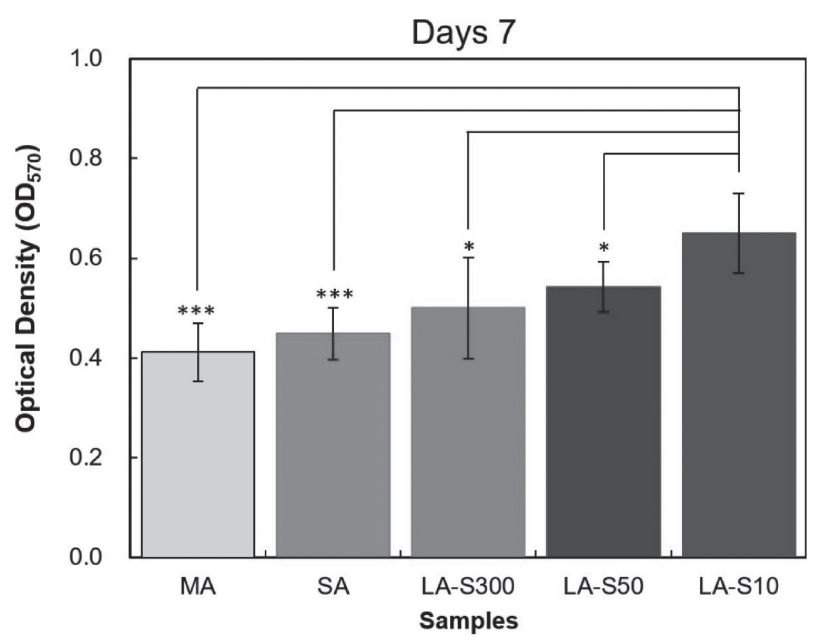

(b)

Fig. 7 (a) MTT results for cell concentrations on MA surface, SA surface and LA surfaces after culturing periods of 1 7 days. (b) Comparison of MTT concentration results for MA, SA and LA samples after culturing period of 7 days $(* \mathrm{p}<0.05, * * * \mathrm{p}<0.001)$.

the SA or MA surface $(p<0.001)$. Moreover, the proliferation rate of the S10 sample is significantly higher than that of the S50 or S300 sample $(p<0.05)$. Consequently, the effectiveness of the deep groove surface structure and nanoscale agglomerates in enhancing the cell proliferation rate is confirmed.

Figure 8 presents SEM images of the MA, SA and LA sample surfaces following culturing for 7 days. It is seen that the cells have a long strip-like morphology in every case. Figure 8(a) shows that the MA surface contains relatively few filopodia and lamellipodia. By contrast, the LA surface contains a large number of filopodia (Fig. 8(b)). Finally, the SA surface shows no obvious pseudopodia (Fig. 8(c)). Overall, the results therefore suggest that the nanosurface of the LA sample is beneficial in promoting cell growth. ${ }^{30}$ )

Chen et al. ${ }^{15)}$ showed that human osteo-sarcoma (HOS) cells seeded on a laser-ablated Ti6Al4V grooved surface showed a strong directional guidance effect; particularly for groove widths in the range of $8 \sim 12 \mu \mathrm{m}$. In general, the topography or roughness of nanoscale surfaces improves cell adhesion and proliferation. In particular, a nanoscale topography alters the protein interaction with the surface. A previous study found evidence of increased osteoblast adhesion on nanosurfaces compared to that of fibroblasts. ${ }^{31)}$ In addition, Matsugaki et al. showed that laser-induced periodic structures induced cell alignment, while surfaces with an anisotropic geometry and a fine-dot structure did not induce a preferential osteoblast orientation. ${ }^{32)}$ In the present study, the nanoscale agglomerates produced by the laser ablation process have an anisotropic structure. Therefore, the cells show no strong orientation effect in the growth process. Comparing the three samples, the MA surface is smooth, while the SA surface has irregular micro-pits, and the LA surface is discontinuous. However, the rat calvarial osteoblasts on the three surfaces all have a long strip-like morphology. In other words, no obvious difference in the cell morphology is observed despite the difference in the surface characteristics. Furthermore, for the LA samples (with groove widths ranging from around $5 \sim 20 \mu \mathrm{m}$ ), no obvious directional guidance of the rat calvarial osteoblast cells is observed. The discrepancy between this finding and as reported previously ${ }^{32}$ is interesting and will be investigated in a future study.

Generally speaking, the adhesion behavior of osteoblasts is more sensitive than that of MG63 cells. ${ }^{33)}$ Therefore, the morphology characteristics of the present osteoblast cells after culturing are significantly different from those of the MG63 cells reported in the literature. ${ }^{33)}$ The ridge width between the grooves is of particular importance in facilitating cellular behavior. ${ }^{34-36)}$ As described above, the present LA samples have a discontinuous groove-like surface structure (S10 and S50) or wave-like structure (S300). It may well be that the discontinuous nature of these surface structures inhibits the spreading of the cells in any particular direction. Moreover, the absence of a strong directional guidance effect

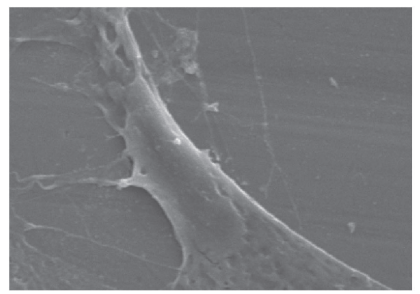

(a)

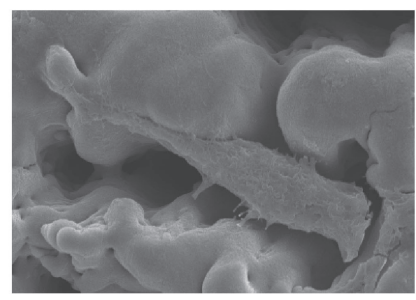

(b)

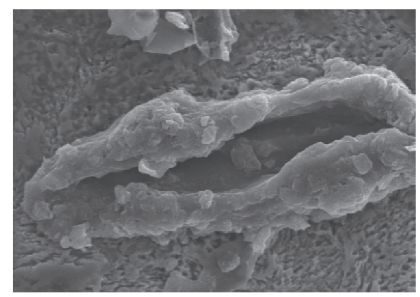

(c)

Fig. 8 SEM images of cells on sample surfaces after culturing period of 7 days: (a) Obvious lamellipodia on MA surface. (b) Large number of filopodia on LA surface. (c) No obvious pseudopodia on SA surface. 
may also suggest that rat calvarial osteoblasts have an inherently low contact sensitivity. However, the published literature contains scant information regarding the effects of LA surface features on osteoblast adhesion and contact guidance. Thus, as commented above, further research is required to clarify this issue in future studies.

Previous studies have reported that the proliferation of osteoblast cells on LA and SA surfaces is the same as that of MG63 cells. Moreover, the proliferation of MG63 cells on a smooth surface is better than that on a LA or SA surface. ${ }^{24,37)}$ Conversely, for mouse osteoblastic (MC3T3-E1) cells and primary human osteoblastic-like cells, rough surfaces have a detrimental effect on the proliferation rate compared to polished surfaces. ${ }^{38)}$ However, in the present study, no significant difference was observed in the early-stage proliferation of rat calvarial osteoblast cells grown on machined surfaces or LA surfaces. A previous study reported that the number of cells on a polished surface after 7 days of culturing was higher than that on a LA surface. ${ }^{39)}$ However, the present results show that the proliferation rate of rat calvarial osteoblasts on LA surfaces is higher than that on SA or MA surfaces. It is speculated that the enhanced proliferation rate is due partially to the rougher surface of the LA samples compared to the SA and MA surfaces and partially to the effects of the nanoscale structures produced on the LA surface in changing the osteoblast response. ${ }^{40)}$

The LA processing of titanium has a particularly beneficial effect on cell proliferation when the pore structure dimension is similar to the cell size. ${ }^{28)}$ The groove widths of the present samples processed using laser travel speeds of S10 and S50 (i.e., $5.44 \sim 16.88 \mu \mathrm{m}$ ) are close to the mouse osteoblast cell size (around $5 \sim 10 \mu \mathrm{m}$ ). Consequently, they provide a better cell growth performance than the sample processed at a higher travel speed of $300 \mathrm{~mm} / \mathrm{sec}$ (groove width 10.97 20.06). Many studies have shown that a microscale surface structure promotes cells growth, proliferation and adhesion. $^{2,41,42)}$ However, in recent years, several studies ${ }^{21,43)}$ have indicated that a nanometer surface structure is also beneficial in enhancing cell proliferation and adhesion since it improves the adsorption behavior of the cellular protein in the growth process. Thus, in comparing the cell proliferation behaviors of the SA and MA samples, an improved performance was observed for the SA sample due to its mixed micro- and nanoscale structure. ${ }^{21,44)} \mathrm{A}$ similar tendency was observed in the study of Gittens et al., ${ }^{17)}$ who used the SA technique to pattern titanium samples with a hybrid micro- and nanoscale structure to promote cell growth. These results, together with those presented in the present study for the LA samples, suggest that a mixed microscale and nanoscale structure is beneficial in improving the biocompatibility of titanium-based bioimplants. Moreover, the effectiveness of the mixed structure in promoting cell proliferation is particularly apparent when the characteristic structure size approaches that of the cells.

Besides the scale of the structures on the sample surface, the geometry and surface topography of the sample also impact the cell growth. Previous studies ${ }^{7,45,46)}$ used various techniques to roughen the sample surface, including SA, titanium plasma-spray, and anodization. It was shown that the SA method produced macro pores with a size of $25 \sim 200 \mu \mathrm{m}$ and micro pores with a scale of $0.5 \sim 2.0 \mu \mathrm{m}$. Sul et al. ${ }^{47)}$ showed that such rough surfaces promote cell adhesion, growth, proliferation and osseointegration both in vivo and in vitro. The present results have shown that LA surface treatment can also promote cell proliferation when the pore dimension is close to the osteoblast cell size. However, the mechanisms of osseointegration are rather complex. Hence, further studies are required to confirm whether the improved cell proliferation rate is accompanied by a better osseointegration performance.

\section{Conclusion}

This study has used a UV laser to ablate the surface of biomedical titanium alloy at various laser travel speeds in the range of $10 \sim 300 \mathrm{~mm} / \mathrm{sec}$. The proliferation rate of rat calvarial osteoblast cells on the ablated surfaces has been investigated and compared with that on sandblasted acidetched (SA) titanium surfaces and machined (MA) titanium surfaces, respectively. In general, the experimental results support the following main conclusions.

(1) The morphology of the LA surface varies significantly with changes in the laser travel speed. For a low speed of $10 \mathrm{~mm} / \mathrm{sec}$, the ablated surface contains groove-like structures with a width of 5.44 10.03 $\mu \mathrm{m}$ and a depthto-width ratio of 4.56 . By contrast, for a high travel speed of $300 \mathrm{~mm} / \mathrm{sec}$, the surface has a shallow wavelike structure with a width of $10.97 \sim 20.06 \mu \mathrm{m}$ and a depth-to-width ratio of just 0.29 . The SA sample contains micro-pits with a diameter of approximately $0.29 \sim 2.58 \mu \mathrm{m}$. Finally, the MA sample has a smooth surface with only minor scratch marks.

(2) The surfaces of the groove and wave structures on the LA samples contain nanoscale agglomerates as a result of the rapid re-solidification which takes place following pulse irradiation. In other words, the LA surfaces have a mixed micro- and nanoscale structure. The agglomerate size increases with a decreasing laser travel speed. In particular, the agglomerate size increases from $30 \mathrm{~nm}$ for the sample processed using a travel speed of $300 \mathrm{~mm} / \mathrm{sec}$ to $100 \mathrm{~nm}$ for the sample ablated using a travel speed of $10 \mathrm{~mm} / \mathrm{sec}$.

(3) The LA surface ablated at a speed of $10 \mathrm{~mm} / \mathrm{sec}$ contains $\mathrm{TiO}$ and $\mathrm{TiN}_{0.3}$ phases in addition to pure titanium. The sample treated at $50 \mathrm{~mm} / \mathrm{sec}$ also contains $\mathrm{TiN}_{0.3}$ phase. However, that treated at $300 \mathrm{~mm} / \mathrm{sec}$ contains only pure Ti. In other words, the samples processed at lower ablation speeds of $10 \mathrm{~mm} / \mathrm{sec}$ and $50 \mathrm{~mm} / \mathrm{sec}$ have a TiO surface oxide film, whereas that processed at $300 \mathrm{~mm} / \mathrm{sec}$ does not.

(4) The MTT assay results have shown that the cell proliferation rate on the LA surfaces is greater than that on the SA or MA surface. In addition, the proliferation rate on the LA sample ablated at 10 $\mathrm{mm} / \mathrm{sec}$ is statistically higher than that on the samples treated at $50 \mathrm{~mm} / \mathrm{sec}$ and $300 \mathrm{~mm} / \mathrm{sec}$, respectively. The improved biocompatibility of the LA-S10 sample can be attributed to the formation of a $\mathrm{TiO}$ layer on the ablated surface, the nanoscale agglomerates on the groove surfaces, and the closer match between the 
groove width $(5.44 \sim 10.03 \mu \mathrm{m})$ and the size of the osteoblast cells $(5 \sim 10 \mu \mathrm{m})$.

\section{Acknowledgment}

The authors would like to thank Biomate Medical Devices Technology Co., Ltd., Taiwan, for the financial support of this study.

\section{REFERENCES}

1) C. Elias, J. Lima, R. Valiev and M. Meyers: JOM 60 (2008) 46-49.

2) Y. Oshida, E.B. Tuna, O. Aktoren and K. Gencay: Int. J. Mol. Sci. 11 (2010) 1580-1678.

3) I. Braceras, J. Alava, J. Oñate, M. Brizuela, A. Garcia-Luis, N. Garagorri, J. Viviente and M. De Maeztu: Surf. Coat. Technol. 158 (2002) 28-32.

4) M. Annunziata, A. Oliva, M.A. Basile, M. Giordano, N. Mazzola, A. Rizzo, A. Lanza and L. Guida: J. Dent. 39 (2011) 720-728.

5) A. Wennerberg and T. Albrektsson: Clin. Oral Implants Res. 20 (2009) $172-184$.

6) I.d.M.O. Bernal, R. Ito, H. Kataki, K. Tsuboi, N. Yamada, T. Tanabe, K. Nagahara and M. Mori: J. Gifu Dent. Soc. 35 (2009) 89-95.

7) L. Le Guéhennec, A. Soueidan, P. Layrolle and Y. Amouriq: Dent. Mater. 23 (2007) 844-854.

8) C.F. Huang, H.C. Cheng, C.M. Liu, C.C. Chen and K.L. Ou: J. Alloys Compd. 476 (2009) 683-688.

9) K.L. Ou, H.H. Chou, C.M. Liu and P.W. Peng: Surf. Coat. Technol. 206 (2011) 1142-1145.

10) W. Soboyejo, B. Nemetski, S. Allameh, N. Marcantonio, C. Mercer and J. Ricci: J. Biomed. Mater. Res. 62 (2002) 56-72.

11) S. Mwenifumbo, M. Li, J. Chen, A. Beye and W. Soboyejo: J. Mater. Sci. 18 (2007) 9-23.

12) J.L. Ricci and H. Alexander: Key Eng. Mater. 198-199 (2001) 179202.

13) W. Soboyejo, C. Mercer, S. Allameh, B. Nemetski, N. Marcantonio and J.L. Ricci: Key Eng. Mater. 198-199 (2001) 203-230.

14) M. Li, N. Morris, S. Mwenifumbo, M.S. Keirstead and W. Soboyejo: LAMP 2002: International Congress on Laser Advanced Materials Processing, (International Society for Optics and Photonics, 2003) pp. 206-211.

15) J. Chen, S. Mwenifumbo, C. Langhammer, J.P. McGovern, M. Li, A Beye and W. Soboyejo: J. Biomed. Mater. Res. B 82 (2007) 360-373.

16) J. Chen, R.A. Bly, M.M. Saad, M.A. AlKhodary, R.M. El-Backly, D.J Cohen, N. Kattamis, M.M. Fatta, W.A. Moore, C.B. Arnold, M.K Marei and W.O. Soboyejo: Mater. Sci. Eng. C 31 (2011) 826-832.

17) R.A. Gittens, T. McLachlan, R. Olivares-Navarrete, Y. Cai, S. Berner, R. Tannenbaum, Z. Schwartz, K.H. Sandhage and B.D. Boyan: Biomaterials 32 (2011) 3395-3403

18) S. Mukherjee, S. Dhara and P. Saha: Int. J. Adv. Manuf. Technol. 76 (2015) 5-15.

19) A. Kurtovic, E. Brandl, T. Mertens and H.J. Maier: Int. J. Adhes Adhes. 45 (2013) 112-117.

20) A.Y. Fasasi, S. Mwenifumbo, N. Rahbar, J. Chen, M. Li, A.C. Beye, C.B. Arnold and W.O. Soboyejo: Mater. Sci. Eng. C 29 (2009) 5-13.

21) W. Zhang, Z. Li, Q. Huang, L. Xu, J. Li, Y. Jin, G. Wang, X. Liu and X. Jiang: Int. J. Nanomedicine 8 (2013) 257-265.
22) A. Joob-Fancsaly, T. Divinyi, A. Fazekas, C. Daroczi, A. Karacs and G. Peto: Smart Mater. Struct. 11 (2002) 819.

23) G. Mendonça, D.B. Mendonça, F.J. Aragao and L.F. Cooper: Biomaterials 29 (2008) 3822-3835.

24) A. Gyorgyey, K. Ungvari, G. Kecskemeti, J. Kopniczky, B. Hopp, A. Oszko, I. Pelsoczi, Z. Rakonczay, K. Nagy and K. Turzo: Mater. Sci. Eng. C 33 (2013) 4251-4259.

25) S.R. Sousa, M. Lamghari, P. Sampaio, P. Moradas-Ferreira and M.A Barbosa: J. Biomed. Mater. Res. A 84 (2008) 281-290.

26) C. Larsson, P. Thomsen, J. Lausmaa, M. Rodahl, B. Kasemo and L. Ericson: Biomaterials 15 (1994) 1062-1074.

27) R.S. Faeda, H.S. Tavares, R. Sartori, A.C. Guastaldi and E. Marcantonio, Jr.: Braz. Oral Res. 23 (2009) 137-143.

28) S. Allegrini, M. Yoshimoto, M.B. Salles, M.R.F. Allegrini, L.C.Y. Pistarini, F.J.C. Braga and A.H.d.A. Bressiani: Appl. Surf. Sci. 307 (2014) 503-512.

29) D.S. Milovanović, S.M. Petrović, M.A. Shulepov, V.F. Tarasenko, B.B. Radak, Š.S. Miljanić and M.S. Trtica: Opt. Laser Technol. 54 (2013) 419-427.

30) D.G. Bello, A. Fouillen, A. Badia and A. Nanci: Acta Biomater. 60 (2017) 339-349.

31) T.J. Webster, C. Ergun, R.H. Doremus, R.W. Siegel and R. Bizios: J. Biomed. Mater. Res. 51 (2000) 475-483.

32) A. Matsugaki, G. Aramoto, T. Ninomiya, H. Sawada, S. Hata and T. Nakano: Biomaterials 37 (2015) 134-143.

33) A. Perez, R. Spears, J. Gutmann and L. Opperman: Int. Endod. J. 36 (2003) 564-570.

34) M. Biggs, R. Richards, S. McFarlane, C. Wilkinson, R. Oreffo and M. Dalby: J. R. Soc. Interface 5 (2008) 1231-1242.

35) K. Matsuzaka, X.F. Walboomers, M. Yoshinari, T. Inoue and J.A. Jansen: Biomaterials 24 (2003) 2711-2719.

36) G. Abagnale, M. Steger, V.H. Nguyen, N. Hersch, A. Sechi, S. Joussen, B. Denecke, R. Merkel, B. Hoffmann and A. Dreser: Biomaterials 61 (2015) 316-326.

37) J. Martin, Z. Schwartz, T. Hummert, D. Schraub, J. Simpson, J. Lankford, D. Dean, D. Cochran and B. Boyan: J. Biomed. Mater. Res. 29 (1995) 389-401.

38) K. Anselme, P. Linez, M. Bigerelle, D. Le Maguer, A. Le Maguer, P. Hardouin, H. Hildebrand, A. Iost and J. Leroy: Biomaterials 21 (2000) 1567-1577.

39) E. Mariscal-Muñoz, C.A. Costa, H.S. Tavares, J. Bianchi, J. Hebling, J.P. Machado, U.H. Lerner and P.P. Souza: Clin. Oral Investig. 20 (2016) 503-511.

40) T.P. Kunzler, C. Huwiler, T. Drobek, J. Vörös and N.D. Spencer: Biomaterials 28 (2007) 5000-5006

41) H.H. Huang, C.T. Ho, T.H. Lee, T.L. Lee, K.K. Liao and F.L. Chen Biomol. Eng. 21 (2004) 93-97.

42) R.L. Sammons, N. Lumbikanonda, M. Gross and P. Cantzler: Clin. Oral Implants Res. 16 (2005) 657-666

43) W. Meng, Y. Zhou, Y. Zhang, Q. Cai, L. Yang, J. Zhao and C. Li J. Bionics Eng. 8 (2011) 234-241.

44) G. Mendonca, D.B. Mendonca, F.J. Aragao and L.F. Cooper: Biomaterials 29 (2008) 3822-3835.

45) E. Conforto, D. Caillard, B. Aronsson and P. Descouts: Eur. Cell Mater. 3 (2002) 9-10.

46) C.J. Ivanoff, G. Widmark, C. Hallgren, L. Sennerby and A. Wennerberg: Clin. Oral Implants Res. 12 (2001) 128-134.

47) Y.T. Sul, C.B. Johansson, Y. Jeong, K. Röser, A. Wennerberg and T. Albrektsson: J. Mater. Sci. 12 (2001) 1025-1031. 